\title{
Mutations in SETD2 and genes affecting histone H3K36 methylation target hemispheric high-grade gliomas
}

\author{
Adam M. Fontebasso - Jeremy Schwartzentruber $\cdot$ Dong-Anh Khuong-Quang $\cdot$ Xiao-Yang Liu $\cdot$ Dominik Sturm • \\ Andrey Korshunov • David T. W. Jones · Hendrik Witt • Marcel Kool · Steffen Albrecht • Adam Fleming • \\ Djihad Hadjadj • Stephan Busche • Pierre Lepage • Alexandre Montpetit • Alfredo Staffa • Noha Gerges • \\ Magdalena Zakrzewska $\cdot$ Krzystof Zakrzewski $\cdot$ Pawel P. Liberski $\cdot$ Peter Hauser $\cdot$ Miklos Garami · \\ Almos Klekner $\cdot$ Laszlo Bognar $\cdot$ Gelareh Zadeh $\cdot$ Damien Faury $\cdot$ Stefan M. Pfister • Nada Jabado • \\ Jacek Majewski
}

Received: 9 January 2013/Revised: 28 January 2013/Accepted: 30 January 2013/Published online: 16 February 2013

(C) The Author(s) 2013. This article is published with open access at Springerlink.com

\begin{abstract}
Recurrent mutations affecting the histone H3.3 residues Lys 27 or indirectly Lys36 are frequent drivers of pediatric high-grade gliomas (over $30 \%$ of HGGs). To identify additional driver mutations in HGGs, we investigated a cohort of 60 pediatric HGGs using whole-exome sequencing (WES) and compared them to 543 exomes from non-cancer control samples. We identified mutations in SETD2, a H3K36 trimethyltransferase, in $15 \%$ of pediatric HGGs, a result that was genome-wide significant $(\mathrm{FDR}=0.029)$. Most SETD2 alterations were truncating mutations. Sequencing the gene in this cohort and another validation cohort (123 gliomas from all ages and grades) showed SETD2 mutations to be specific to high-grade
\end{abstract}

A. M. Fontebasso and J. Schwartzentruber contributed equally to this work.

S. M. Pfister, N. Jabado, J. Majewski are co-senior and cocorresponding authors.

Electronic supplementary material The online version of this article (doi:10.1007/s00401-013-1095-8) contains supplementary material, which is available to authorized users.

A. M. Fontebasso · N. Jabado ( $\square)$

Division of Experimental Medicine, McGill University and

McGill University Health Centre, Montreal, QC, Canada

e-mail: nada.jabado@mcgill.ca

J. Schwartzentruber $\cdot$ P. Lepage · A. Montpetit - A. Staffa . J. Majewski $(\square)$

McGill University and Genome Quebec Innovation Centre,

Montreal, QC, Canada

e-mail: jacek.majewski@mcgill.ca

D.-A. Khuong-Quang · X.-Y. Liu - D. Hadjadj · S. Busche ·

N. Gerges · D. Faury · N. Jabado · J. Majewski

Department of Human Genetics, McGill University and McGill

University Health Centre, Montreal, QC, Canada tumors affecting $15 \%$ of pediatric HGGs (11/73) and $8 \%$ of adult HGGs $(5 / 65)$ while no SETD2 mutations were identified in low-grade diffuse gliomas (0/45). Furthermore, SETD2 mutations were mutually exclusive with $H 3 F 3 A$ mutations in HGGs $(P=0.0492)$ while they partly overlapped with IDHI mutations (4/14), and SETD2mutant tumors were found exclusively in the cerebral hemispheres $(P=0.0055)$. SETD2 is the only H3K36 trimethyltransferase in humans, and SETD2-mutant tumors showed a substantial decrease in H3K36me3 levels $(P<0.001)$, indicating that the mutations are loss-offunction. These data suggest that loss-of-function SETD2 mutations occur in older children and young adults and are specific to HGG of the cerebral cortex, similar to the H3.3 G34R/V and IDH mutations. Taken together, our results suggest that mutations disrupting the histone code at H3K36, including H3.3 G34R/V, IDH1 and/or SETD2 mutations, are central to the genesis of hemispheric HGGs in older children and young adults.

Keywords High-grade glioma $\cdot$ H3K36 methylation · SETD2 $\cdot$ Epigenetic $\cdot$ Pediatric $\cdot$ Young adult

D. Sturm · D. T. W. Jones - H. Witt - M. Kool ·

S. M. Pfister $(\bowtie)$

Division of Pediatric Neurooncology, German Cancer Research

Center (DKFZ), Heidelberg, Germany

e-mail: s.pfister@dkfz-heidelberg.de

A. Korshunov

Clinical Cooperation Unit Neuropathology, German Cancer

Research Center (DKFZ), Heidelberg, Germany

H. Witt · S. M. Pfister

Department of Paediatric Oncology, Hematology and Immunology, Heidelberg University Hospital, Heidelberg, Germany 


\section{Introduction}

Malignant primary brain and central nervous system (CNS) tumors occur at an age-adjusted incidence rate of 7.3 out of 100,000 people across all ages and are the leading cause of cancer-related death in children [9]. High-grade gliomas [HGG; grade III and grade IV astrocytomas/glioblastoma $(\mathrm{GBM})]$ are highly aggressive and deadly brain tumors [9, 32] and are more commonly diagnosed in adults. GBM remains essentially incurable despite decades of concerted therapeutic efforts [5]. One impediment to treatment is that GBM is diagnosed as a single pathological entity, which cannot discriminate potential genetic drivers and molecular subtypes. This impacts the design and outcome of clinical trials and likely contributes to the apparent inherent resistance of GBM to adjuvant therapies. Because of the similar histology, current treatments for GBM in children are driven by adult studies and show, as in adults, little therapeutic success.

We and others recently identified two recurrent mutations in $H 3 F 3 A$, which encodes the replication-independent histone 3 variant $\mathrm{H} 3.3$, in over $30 \%$ of pediatric and young adult GBM [32, 42]. The mutations, K27M and G34R/ $\mathrm{G} 34 \mathrm{~V}$, occur at positions in the histone tail that are critical for post-translational modifications involved in the histone code, which determines chromatin structure and gene expression. H3.3 K27M mutations were also identified in over $70 \%$ of pediatric diffuse intrinsic pontine glioma (DIPG), a fatal HGG of the brainstem [18, 42] as well as K27M mutations in the canonical H3.1 in $18 \%$ of samples [42]. H3.3 mutations significantly overlapped with mutations in TP53 and in ATRX ( $\alpha$-thalassemia/mentalretardation syndrome-X-linked) $[13,40]$ and less frequently with the ATRX hetero-dimer $D A X X$, which encode subunits of a chromatin remodeling complex required for

\footnotetext{
S. Albrecht

Department of Pathology, Montreal Children's Hospital, McGill

University Health Centre, Montreal, QC, Canada

A. Fleming $\cdot$ N. Jabado

Division of Hemato-Oncology, Montreal Children's Hospital,

McGill University Health Centre, Montreal, QC, Canada
}

M. Zakrzewska · P. P. Liberski

Department of Molecular Pathology and Neuropathology,

Medical University of Lodz, Lodz, Poland

K. Zakrzewski

Department of Neurosurgery, Polish Mother's Memorial

Hospital Research Institute, Lodz, Poland

P. Hauser · M. Garami

2nd Department of Paediatrics, Semmelweis University,

Budapest, Hungary
H3.3 incorporation at pericentric heterochromatin and telomeres [8, 13]. H3.3 mutations represent the pediatric counterpart of the recurrent hotspot mutations in isocitrate dehydrogenase 1 or $2(I D H 1 / 2)$ [27, 44]. IDHI R132 mutations are gain-of-function, causing the enzyme to produce 2-hydroxyglutarate (2-HG) [7, 27] and IDHImutant tumors display distinct DNA methylation profiles with global hypermethylation, termed a glioma-CpG island methylator phenotype (G-CIMP) [26, 35, 38]. Interestingly, similar to pediatric GBM, IDH1 mutations were shown to occur in association with TP53 [3, 27] and ATRX mutations in adult diffuse astrocytic tumors [14, 16, 25], illustrating an important constellation of mutations in the development of pediatric and secondary GBM. In the present study, we sought to identify drivers of HGG in pediatric samples that did not carry H3.3 or IDH mutations. We investigated a cohort of 60 pediatric HGGs utilizing statistical analysis of whole-exome sequencing (WES) on a genome-wide ranking scale and validated results in an independent validation cohort of 123 gliomas from all ages and grades. Herein, we present data showing the importance and functional impact of mutations in the $\mathrm{H} 3 \mathrm{~K} 36$ trimethyltransferase SETD2 in HGGs of the cerebral hemispheres.

\section{Materials and methods}

Sample characteristics and pathological review

Samples were obtained with informed consent following approval of the Institutional Review Board of individual hospitals. Samples were reviewed by senior neuropathologists (S.A., A.K.) according to WHO guidelines. Fiftyone pediatric grade IV astrocytomas (glioblastoma, GBM) patients and nine pediatric grade III astrocytomas from 
patients aged 1-20 years were analyzed by whole-exome sequencing (44 previously published in [32]). An additional 123 adult and pediatric gliomas of diverse histology and grade were also included for targeted sequencing of SETD2, IDHI and H3F3A. Available clinical and relevant mutational characteristics are detailed in Table S1. Tissues were obtained from the London/Ontario Tumor Bank, the Pediatric Cooperative Health Tissue Network, the Children's Oncology Group, The Montreal Children's Hospital and from collaborators in Poland, Hungary and Germany.

\section{DNA extraction}

Genomic DNA was extracted from frozen tumor tissue utilizing the Qiagen DNeasy Blood and Tissue kit according to instructions from the manufacturer (Qiagen).

\section{Alignment and variant calling for whole-exome sequencing}

Standard instructions from the manufacturer were used for target capture with the Illumina TruSeq exome enrichment kit and 100 bp paired-end sequencing reads on the Illumina HiSeq platform with bioinformatic processing and variant annotation as previously described [32]. For the selected genes of interest shown in Table S1, variants in these genes that were private to tumor samples are shown, i.e. those variants not seen within the 1000 genomes (http://www. 1000genomes.org/) or NHLBI exome (http://evs.gs. washington.edu/EVS/) databases, or in any of our 543 control exomes. Missense mutations were highlighted if they occurred within highly conserved residues in vertebrates, assessed utilizing the UCSC Genome Browser (http:// genome.ucsc.edu/) conservation track tool [17]. To assess significance of mutations in our tumor dataset, we used a case-control approach to compare the frequency of private mutations in each gene in the 60 tumor exomes to 543 control exomes, which were from constitutional DNA of patients with Mendelian diseases also sequenced at the McGill University and Genome Quebec Innovation Centre (Table S2). We controlled for false discovery rate using the Benjamini-Hochberg procedure. All variants in these genes are detailed in Table $\mathrm{S} 2$, whereas only private variants, likely to be somatic, and in highly conserved residues (likely to impact function), are highlighted in Table S1 and discussed in this study.

Targeted next-generation sequencing of SETD2

Coding regions of SETD2 were amplified using the Fluidigm. Access Array system (http://www.fluidigm.com/ access-array-system.html) and sequenced on a half run of the GS FLX Titanium system from Roche 454. Forty pairs of primers were designed to cover all coding regions of the 21 exons of SETD2. Primers were designed using Primer3 (http://frodo.wi.mit.edu/primer3/) [28]. The parameters were set to achieve melting temperatures ranging from 57 to $59{ }^{\circ} \mathrm{C}$. Lengths of PCR products are between 197 and 394 bp. The UCSC Genome Browser (http://genome.ucsc. edu/) was used to download target genomic regions prior to design and identify variants (based on dbSNP135: http:// www.ncbi.nlm.nih.gov/projects/SNP/) [17]. PCRs were performed on $48 \times 48$ IFC (Integrated Fluidic Circuit) chips. On each chip, 40 regions were amplified in 48 samples. Amplification of target regions and addition of 454 sequencing adapters and individual bar codes occur in the same PCR performed on the Fluidigm FC1 cycler. All samples were individually bar coded and sequenced in one half-region of a GS FLX Titanium run. Validation of variants was done with Sanger sequencing. Following this, statistical analyses of Fisher's exact test for contingency comparisons were performed utilizing GraphPad Prism 5 software.

Immunoblotting analysis of H3K36me3 levels in patient tumors

Fresh-frozen tumor tissues with adequate material and known SETD2, H3F3A and IDH1 mutational status were lysed using the EpiQuik Total Histone Extraction Kit (Epigentek, USA). Lysates were quantified utilizing standard BioRad protein assay (BioRad) and loaded onto $15 \%$ acrylamide gels and run for $2 \mathrm{~h}$ at $100 \mathrm{~V}$. Proteins were transferred to polyvinylidene difluoride (PVDF) membranes at room temperature for $5 \mathrm{~min}$, using the TransBlot Turbo transfer system (BioRad) at LOW MW setting, blocked and immunoblotted with the following conditions overnight at $4{ }^{\circ} \mathrm{C}$ : rabbit polyclonal anti-H3K36me3 (Abcam \#9050) at 1:1,000 in 5\% skim milk and rabbit polyclonal anti-H3 (Abcam \#1791) at 1:1,000 in $5 \%$ skim milk. Membranes were subsequently washed thrice with tris-buffered saline-Tween 20 (TBS-T) and incubated with horseradish peroxidase (HRP)-conjugated donkey anti-rabbit IgG secondary antibody (GE Healthcare \#NA934V) at 1:5,000 with Precision Protein StrepTactinHRP conjugate at 1:10,000 (BioRad \#161-0380) in 5\% skim milk for $1 \mathrm{~h}$ at room temperature and revealed utilizing Amersham ECL detection (Amersham Biosciences). H3K36me3 bands from four independent blots were quantified utilizing ImageQuant TL v2003.02 (Amersham Biosciences), normalized to total $\mathrm{H} 3$, and normalized ratios were compared statistically using two-tailed $T$ test for significance. 
Methylation array profiling

DNA extracted from a subset of pediatric HGGs demonstrating defects in SETD2, IDH1, or H3F3A at G34 and wild-type tumors $(n=36)$ was analyzed for genome-wide DNA methylation patterns utilizing the HumanMethylation450 BeadChip according to the manufacturer's instructions (Illumina, San Diego, USA) at the McGill University and Genome Quebec Innovation Centre. Of the $>480,000$ probes on the methylation chip, we discarded probes with $\geq 90 \%$ sequence similarity to multiple genomic locations, with sequence variants in the probe binding region (1000 Genomes Project, SNPs with a minor allele frequency $\geq 2 / 120$ ), and probes located on sex chromosomes, leaving 392,904 autosomal probes for further analysis. Subset-quantile within array normalization was performed on beta values using the SWAN method [23]. For unsupervised hierarchical clustering, the top 8,000 most variable probes (by standard deviation) were utilized with average linkage and Pearson correlation algorithms across the dataset. Consensus clustering was performed utilizing the $k$-means algorithm with 1,000 iterations on the top 8,000 most variable probes in the dataset. Methylation analysis was performed utilizing $\mathrm{R}$ ( $\mathrm{R}$ version 2.14.2, http://cran.r-project.org/) with Minfi and ConsensusClusterPlus loaded packages.

\section{Results and discussion}

SETD2 mutations affect a significant proportion of pediatric HGGs

To identify genetic drivers in samples not carrying mutations in $I D H I$ and $H 3 F 3 A$, we analyzed 60 pediatric HGG tumors [grades III $(n=9)$ and IV $(n=51)$ ] using WES (44 previously reported; Table S1) [32]. As matched normal DNA was unavailable for the majority of tumors, we identified private mutations that were present in tumors but were absent from public databases (1000 genomes project [24], NHLBI exomes) and from our set of 543 control exomes, and considered these as candidate somatic mutations. We compared the frequency of private mutations in each gene between the 60 tumors and 543 controls using Fisher's exact test and used a false discovery rate threshold (FDR) of 0.05 to correct for multiple tests. Our case-control approach effectively corrects for the background rate of mutations in each gene (which implicitly includes the length of the gene and the mutability). We filtered out variants that were predicted to be tolerated/benign/unknown by both SIFT and PolyPhen-2 [1], and identified private mutations that we considered as candidate somatic mutations. The top genes by mutation frequency are shown in
Table S2. As expected, four genes previously associated with pediatric HGG showed a highly significantly number of mutations (TP53, H3F3A, ATRX, NF1) [32] (Table S2). In addition, two genes not previously reported in HGG, SETD2 and CSMD3, achieved genome-wide significance $(\mathrm{FDR}=0.029$ and 0.031, respectively). For SETD2, this significance was more striking when only truncating mutations were considered (FDR $=0.0017)$, as no truncating mutations were seen in 543 controls, but tumor samples had frameshift (3), nonsense (1), and splicing (1) variants. In addition, the three missense variants in tumor samples occurred at highly conserved residues and were computationally predicted as damaging by both SIFT and Polyphen scores (Fig. 1a, b). In contrast, of the seven private variants in the control samples (all missense), only one is predicted damaging by both SIFT and Polyphen. H3.3 mutations occur at two positions within the histone tail involved in key regulatory post-translational modifications, K27 (directly) and K36 (indirectly). Driver loss-of-function SETD2 mutations have recently been identified in two highgrade cancers, renal cell carcinoma $[6,12]$ and early T-cell precursor acute lymphoblastic leukemia [37]. The other candidate gene, CSMD3 is expressed in adult and fetal brains; however, its functions are yet unclear [33]. Hence, we focused our next efforts on SETD2 as the top candidate gene.

SETD2 mutations affect pediatric and adult HGGs of the cerebral hemispheres

We expanded our sequencing analysis and next sequenced SETD2 in 123 additional gliomas of various ages and grades (Table 1; Table S1). Combining the discovery and the validation datasets, SETD2 mutations were identified in a total of $15 \%$ of pediatric HGG (11/73) and $8 \%$ of adult HGG $(5 / 65)$, and were not seen in low-grade diffuse gliomas $(0 / 45)$ $(P=0.0133$; Table 1; Table S1). Except for one sample, all mutations occurred in children above the age of 12, in adolescents and in younger adults, mirroring the age range of H3.3 G34R/V and IDH1 mutations in HGG (Fig. 1a; Figure S1) [18-21, 32, 35]. Notably, all tumors carrying SETD2 mutations were localized in the cerebral hemispheres $(P=0.0055)$. SETD2 mutations were mutually exclusive with $H 3 F 3 A$ mutations $(P=0.049)$ in HGGs $(0 / 70)$, but showed partial overlap with IDHI R132 mutations (4/14), TP53 (4/8) and ATRX (3/9) mutations (Table S1).

Missense/truncating mutations in SETD2 impair trimethyltransferase activity of the enzyme and confer distinct global DNA methylation signatures

SETD2 encodes the only $\mathrm{H} 3 \mathrm{~K} 36$ trimethyltransferase in humans [11,41]. To support computational predictions of 
Fig. 1 Missense/truncating mutations of the $\mathrm{H} 3 \mathrm{~K} 36$ trimethyltransferase SETD2 identified in pediatric and adult high-grade gliomas. a Patient age, tumor grade, and affected brain region of tumors with SETD2 mutation. b Schematic mapping type and distribution of missense/truncating mutations in SETD2 in 183 gliomas included in the study

\begin{tabular}{|cccc|}
\hline $\mathbf{a}$ Age & Grade & SETD2 Mutation & Brain Region \\
\hline 1 & IV & p.R1686Q & Frontal lobe \\
12 & IV & p.P1470S & Temporal lobe \\
12 & IV & p.(S1002Ffs 4$)$ & Parietal lobe \\
12 & IV & p.1385_1385del, p.R2490Q & Frontal lobe \\
12 & III & p.G1621R & Cortex \\
14 & IV & p.R2109X & Temporal lobe \\
14 & IV & p.V2272A & Cortex \\
15 & IV & NM_014159.6:C.6293+1G $>$ A & Frontal lobe \\
17 & IV & p.(T305Qfs 35$)$ & Temporal lobe \\
17 & III & p.(K583Sfs*17) & Temporo-parietal lobe \\
18 & IV & p.E498X & Temporal lobe \\
43 & III & p.(S342Qfs*17) & Temporal lobe \\
48 & IV & p.(K853Rfs 37$)$ & Occipital lobe \\
50 & IV & p.S1660X & Parietal lobe \\
53 & IV & p.D868G & Parietal lobe \\
58 & III & p.R1625C & Insular cortex \\
\hline
\end{tabular}

b

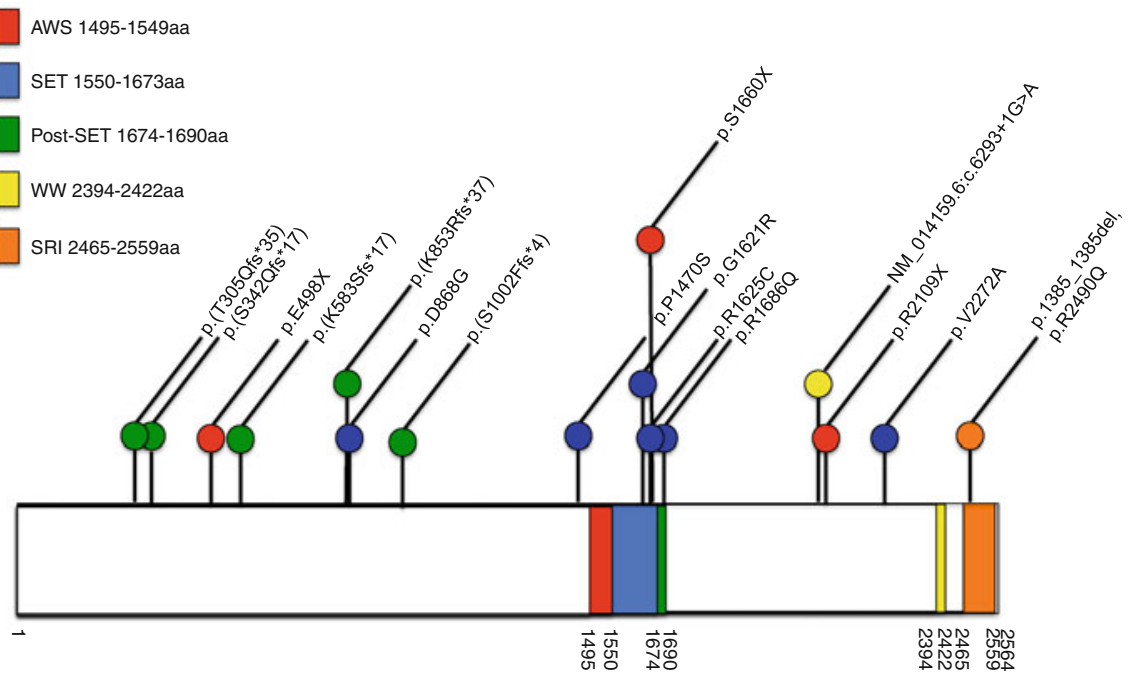

SETD2

Missense $\bigcirc$ Frameshift $\bigcirc$ splicing $\bigcirc$ Indel

Table 1 Frequencies of SETD2 mutations in 183 pediatric and adult gliomas

\begin{tabular}{lcccc}
\hline Glioma & Mutated & Wild type & Total & Frequency (\%) \\
\hline Grade IV & 12 & 85 & 97 & 12.37 \\
Pediatric & 9 & 51 & 60 & 15 \\
Adult & 3 & 34 & 37 & 8.11 \\
Grade III & 4 & 37 & 41 & 9.76 \\
Pediatric & 2 & 11 & 13 & 15.38 \\
Adult & 2 & 26 & 28 & 7.14 \\
Grade II & 0 & 45 & 45 & 0 \\
Pediatric & 0 & 23 & 23 & 0 \\
Adult & 0 & 22 & 22 & 0 \\
Overall gliomas & 16 & 167 & 183 & 8.7 \\
\hline
\end{tabular}

the damaging nature of SETD2 mutations, we assessed H3K36 trimethyltransferase activity in histone acidic extractions of patient tissue samples through Western blotting for H3K36me3 levels, an indicator of SETD2 activity [11]. Immunoblot analysis revealed a significant decrease in total H3K36me3 levels in SETD2-mutant gliomas (Fig. 2a), as well as a significantly decreased normalized ratio of H3K36me3 to total H3 levels in SETD2-mutant tumors $(P<0.001$; Fig. 2b) showing loss-of-function as a result of SETD2 missense/truncating mutations.

GBMs with epigenetic driver mutations such as H3.3 $\mathrm{K} 27 \mathrm{M}$ or $\mathrm{G} 34 \mathrm{R} / \mathrm{V}$, as well as those with IDH1 mutations, display distinct DNA methylation profiles and clinical characteristics. They also arise in distinct anatomic compartments, with IDH1- and H3.3 G34R/V-mutant tumors 

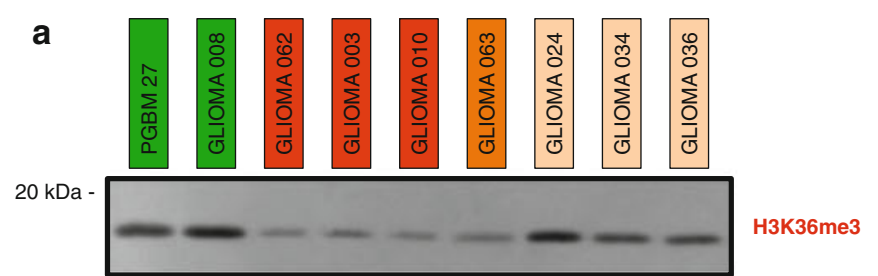

$20 \mathrm{kDa}$

$15 \mathrm{kDa}$

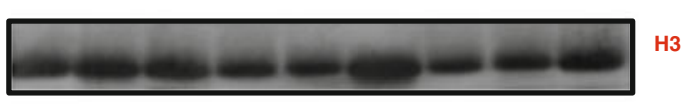

WT

SETD2 MUT

SETD2-IDH1 MUT

IDH1 MUT

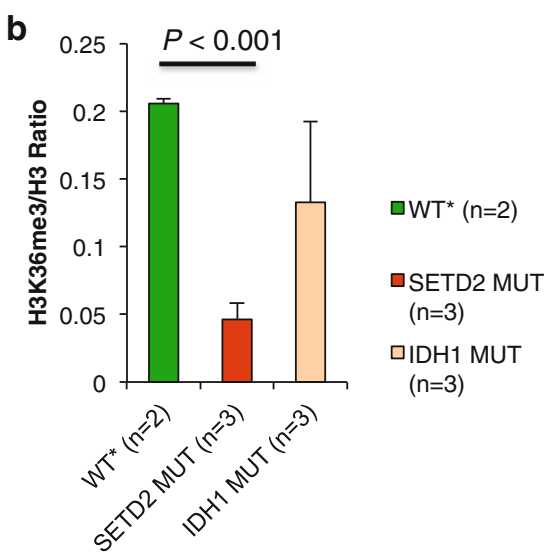

C

Pediatric Hemispheric HGG $(n=35)$

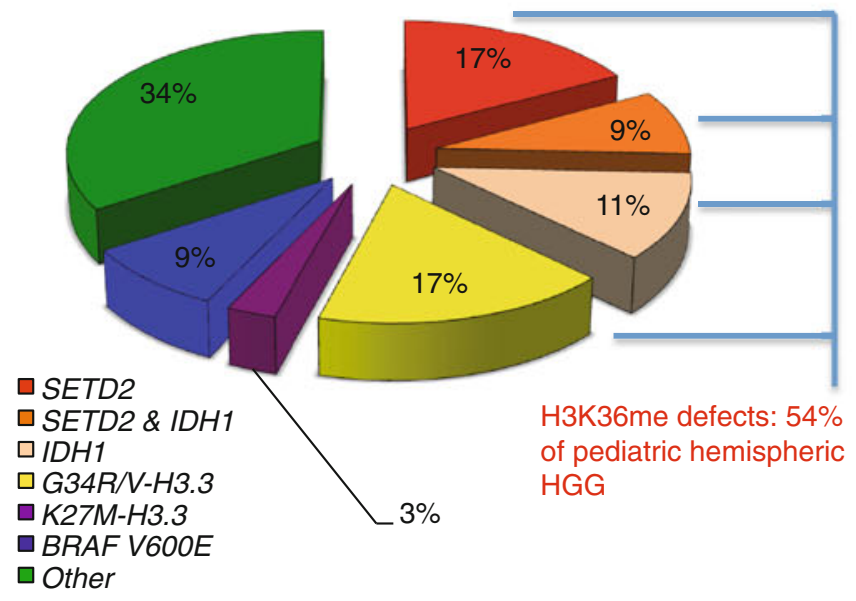

d

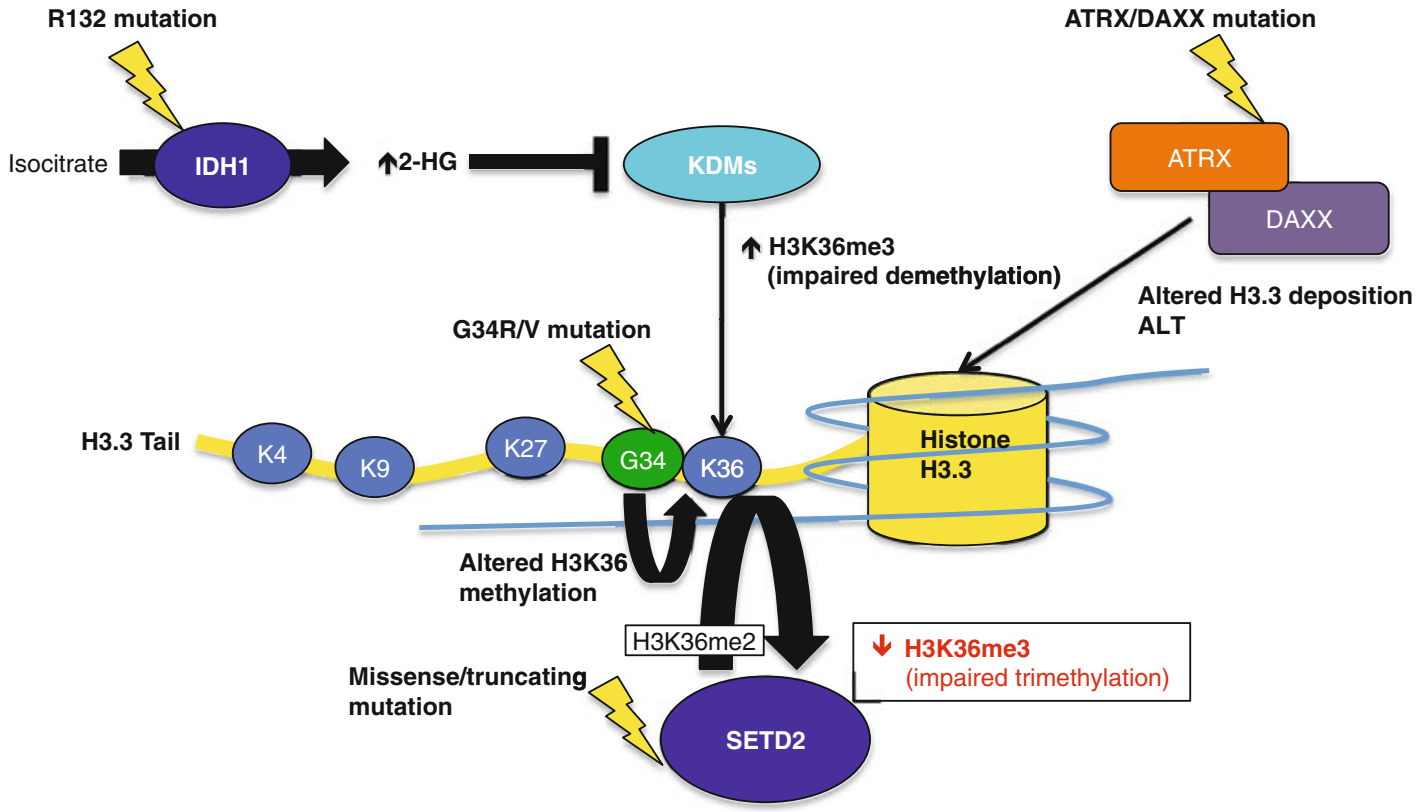


4Fig. 2 Missense/truncating mutations in SETD2 impair H3K36 trimethyltransferase activity of the enzyme. a Western blot analysis of histone acidic extracts of SETD2-mutant tumor samples demonstrating a significant decrease in $\mathrm{H} 3 \mathrm{~K} 36 \mathrm{me} 3$ levels, indicating impaired H3K36 trimethyltransferase activity of the enzyme. b Densitometric quantification of $\mathrm{H} 3 \mathrm{~K} 36 \mathrm{me} 3$ levels assessed in four independent blots demonstrating a significant decrease in H3K36me3/Total H3 normalized ratios in SETD2-mutant tumors. $\mathrm{WT}^{*}=\mathrm{WT}$ for SETD2, IDH1 and H3F3A. c Pie representation of mutations directly or indirectly affecting H3K36 methylation (H3K36me) in pediatric HGGs of the cerebral hemispheres $(n=35)$ indicating that approximately half of these tumors display defects, pointing to $\mathrm{H} 3 \mathrm{~K} 36$ dysregulation as a critical mechanism of hemispheric high-grade gliomagenesis. d Schematic representation of major genetic and epigenetic defects leading to altered $\mathrm{H} 3 \mathrm{~K} 36$ methylation in hemispheric HGGs

being restricted to areas of the cerebral hemispheres [18-21, $32,35]$. We and others have previously described the distinct heterogeneity of epigenetic profiles underlying HGGs including GBM $[2,35,36]$. We thus sought to characterize the DNA methylation profiles of 36 pediatric HGG tumors with mutations likely to affect K36 methylation status, using the Illumina $450 \mathrm{~K}$ array platform as previously described [35]. SETD2 mutations yielded global DNA methylation patterns distinct from tumors with $\mathrm{H} 3.3 \mathrm{G} 34 \mathrm{R} /$ $\mathrm{V}$ mutations, but which partly overlapped with IDHImutant methylation patterns (Fig. 3a-f). Notably, promoters at $O L I G 1 / 2$ loci, characteristically hypermethylated in G34R/V-mutated samples, were not hypermethylated in SETD2 mutants (Figure S2) [2, 35].

Mutations identified in candidate oncogenic drivers and other genes involved in histone post-translational modifications in HGGs

We further investigated our dataset for mutations in other genes affecting PTM of $\mathrm{H} 3 \mathrm{~K} 27$ or H3K36 but which did not reach the statistically significant mutation levels. Eight distinct mammalian enzymes methylate H3K36 and share the catalytic SET domain, but have varying preferences for K36 residues in different methylation states (reviewed in [41]). SETD2 is the only enzyme in humans to catalyze H3K36 tri-methylation [11], while its mono- and/or di-methylation is catalyzed by NSD1, NSD2, NSD3, SETMAR, ASH1L, SMYD2 or SETD3 (reviewed in [41]). We identified one missense and one nonsense mutation in ASHIL (concurrently with SETD2 mutation) and SETD3 (1 missense mutation concurrently with SETD2 mutation). One PGBM mutant for SETD2 also had a missense mutation in UTX/KDM6A (H3K27 demethylase). This same PGBM had a missense mutation in PBRMI, a gene frequently mutated in renal cell carcinoma in association with SETD2 [39]. We also identified two mutations in KDM5C (H3K4 demethylase) (Table S1). Interestingly, no mutations in the cancer-implicated histone methyltransferase $E Z H 2$ were identified. Mutations in these genes were not prevalent enough to be statistically associated with HGGs in our sample set; however, it remains possible that they contribute to pathogenesis in a small fraction of HGG cases.

Further investigation of the exome dataset revealed previously described mutations in BRAF (V600E [30, 31], $5 / 60$ pediatric $\mathrm{HGG}$ ), which did not overlap with the epigenetic driver mutations we identify (Table S1; Fig. 2c). Other alterations also previously described in GBM, which may provide pathways alternative or complementary to epigenomic dysregulation, included PTEN mutations (two samples) which overlapped with $\mathrm{H} 3.3 \mathrm{~K} 27 \mathrm{M}$ while $E G F R$ mutation or amplification (three samples) and CDKN2A mutation/loss (five samples) partially overlapped with SETD2 mutations (Table S1). Truncating mutations in the mismatch repair genes [10] MSH6 (three samples) and MSH2 (one sample) were identified and were concurrent with IDH1 (two samples) and SETD2 (three samples) mutations. Of note, SETD2 mutations were absent in a large cohort of 125 cases of medulloblastoma [15] another major group of pediatric brain tumors.

Alteration of $\mathrm{H} 3 \mathrm{~K} 36$ post-translational modifications characterize hemispheric adolescent and younger adult HGG

Post-translational modification of resident histones modulates the properties of chromatin, impacting cell state and differentiation and determining the outcome of virtually all DNA processes in eukaryotes. Methylation of H3K36 is a key histone mark and has been widely associated with active chromatin but also with transcriptional repression, alternative splicing, DNA replication and repair, DNA methylation and the transmission of memory of gene expression from parents to offspring during development (reviewed in [41]). We identify loss-of-function mutations in SETD2, in $15 \%$ of pediatric and $8 \%$ of adult high-grade gliomas in a cohort of 183 samples from all ages and grades II-IV of glioma (Fig. 1a; Table S1). We further show SETD2 mutations to be specific to high-grade tumors $(P=0.013)$, to HGGs located within the cerebral hemispheres $(P=0.005)$, and to be mutually exclusive with H3.3 mutations we [18, 32] and others [42] previously identified in pediatric high-grade astrocytomas $(P=$ 0.049). SETD2 alterations overlapped with $I D H 1$ mutations in 4 of 14 tumors (Table S1). Strikingly, the oncometabolite produced by IDHI mutations inhibits a plethora of histone demethylases (KDMs) causing aberrant histone methylation at defined residues including K27 and K36 and a block to cell differentiation [4, 22, 29, 43]. We [21] and others [14] have previously shown the association of ATRX 

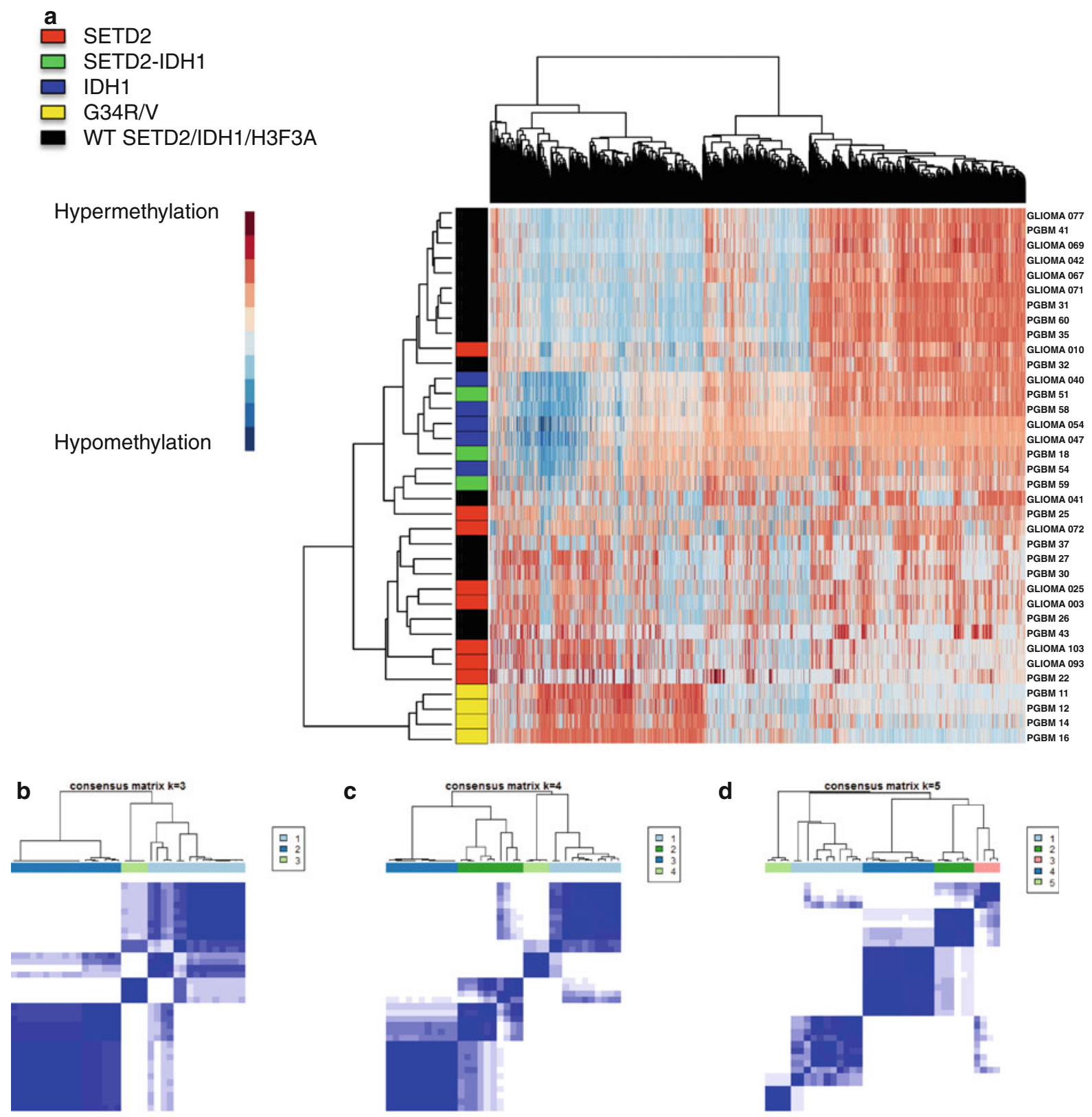

\begin{tabular}{|l|}
\hline 믈 \\
2 \\
ㅁ․ \\
\hline
\end{tabular}

C

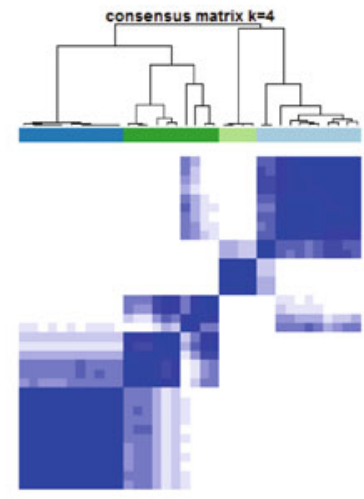

d
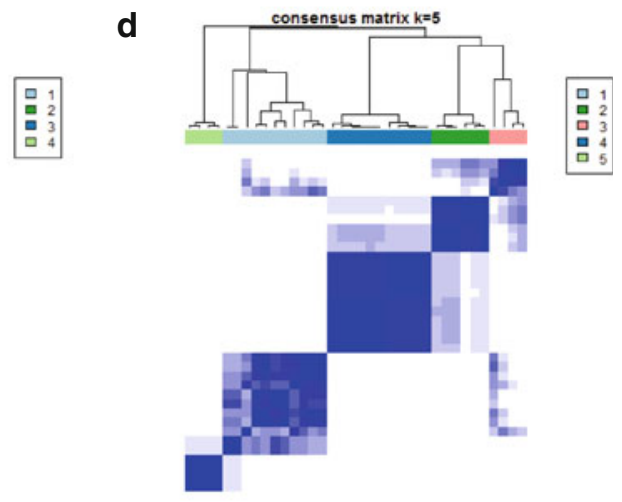

e

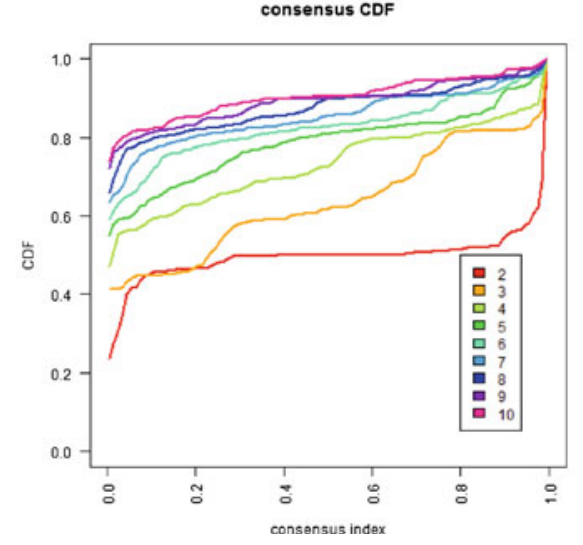

f

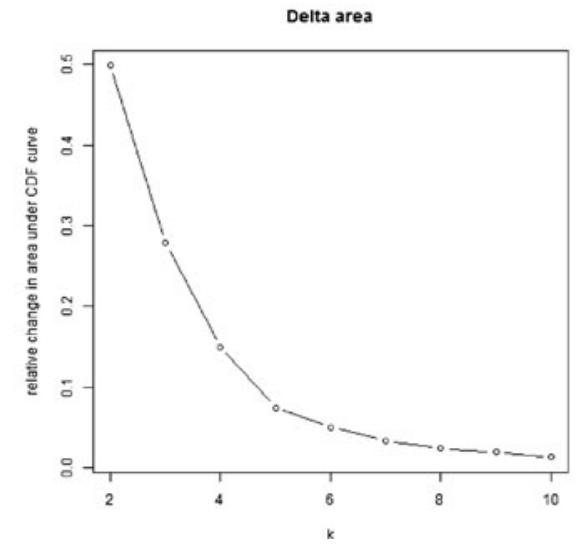


4Fig. 3 Mutations affecting H3K36 methylation confer distinct global DNA methylation signatures. a Unsupervised hierarchical clustering of methylation Beta-values representing the top 8,000 most variable probes between samples mutated for SETD2, IDH1 or H3.3 G34R/V and high-grade gliomas wild-type (WT) for these genes $(n=36)$. b $k$ means consensus matrices for $k=3(\mathbf{b}), k=4$ (c) or $k=5$ (d) for the top 8,000 most variable probes. e Empirical cumulative distribution function $(\mathrm{CDF})$ plot and delta area differences (f) for indicated numbers of clusters $(k=2$ to $k=10)$

and TP53 mutations in IDHI-mutant diffuse astrocytic gliomas, and others have pointed to mutations in $C I C$ and $1 \mathrm{p} 19 \mathrm{q}$ loss in $\mathrm{IDH} 1$-mutant oligodendroglial tumors. Thus, IDH1 mutations may require other key genetic events in a specific context for full-blown tumorigenesis, which may include SETD2 mutations as suggested by our cohort. H3.3K36 methylation can be thus disrupted by H3.3 G34R/ $\mathrm{V}$ mutation, IDH mutations and the SETD2 mutations we report herein (Fig. 2a, b). Furthermore, our current analysis suggests that this histone mark is specifically altered in hemispheric adolescent and younger adult HGG (Fig. 2c, d) $[2,18,19,25,32,34,35]$, and that the functional effect differs between SETD2 and H3.3 mutations (Fig. 3; Figure S2). Future studies directed towards elucidating the importance of $\mathrm{H} 3 \mathrm{~K} 36$ methylation in cortical astrocytes and neural progenitor cells, and its dysregulation in tumorigenesis may lend insight into the regional specificity of these defects, while improved understanding of the consequences of altered chromatin remodeling induced by these mutations will help guide alternative therapeutic avenues for these deadly cancers.

Acknowledgments The authors would like to acknowledge the excellent staff of the McGill University and Genome Quebec Innovation Centre High-Throughput sequencing platform for performing the exome capture and sequencing. This work was supported by the Cole Foundation, and was funded by Genome Canada and the Canadian Institute for Health Research (CIHR) with co-funding from Genome BC, Genome Quebec, CIHR-ICR (Institute for Cancer Research) and C17, through the Genome Canada/CIHR joint ATID Competition [project title: The Canadian Paediatric Cancer Genome Consortium: Translating next-generation sequencing technologies into improved therapies for high-risk childhood cancer (NJ)], the Hungarian Scientific Research Fund (OTKA) Contract No. T-04639, TAMOP-4.2.2.A-11/1/KONV-2012-0025, the National Research and Development Fund (NKFP) Contract No. 1A/002/2004 (PH, MG, LB), the PedBrain project contributing to the International Cancer Genome Consortium funded by the German Cancer Aid (109252) and the CNS tumor tissue bank within the priority program on tumor tissue banking of the German Cancer Aid (108456), the BMBF, the Samantha Dickson Brain Tumor Trust, and a grant from the National Cancer Center Heidelberg ("Paediatric Brain Tumor Preclinical Testing"). A. Fontebasso and X-Y. Liu are the recipients of studentship awards from CIHR. DA Khuong-Quang is the recipient of a studentship from the Fonds de la recherche en santé du Québec (FRSQ). S. Pfister is the recipient of the Sybille Assmus Award for Neurooncology in 2009 and N. Jabado is the recipient of a Chercheur Clinicien Award from Fonds de Recherche en Santé du Québec and an award from the Canadian Gene Cure Foundation.
Conflict of interest The authors declare no competing financial interests.

Open Access This article is distributed under the terms of the Creative Commons Attribution License which permits any use, distribution, and reproduction in any medium, provided the original author(s) and the source are credited.

\section{References}

1. Adzhubei IA, Schmidt S, Peshkin L, Ramensky VE, Gerasimova A, Bork P, Kondrashov AS, Sunyaev SR (2010) A method and server for predicting damaging missense mutations. Nat Methods 7(4):248-249. doi:10.1038/nmeth0410-248

2. Cha TL, Zhou BP, Xia W, Wu Y, Yang CC, Chen CT, Ping B, Otte AP, Hung MC (2005) Akt-mediated phosphorylation of EZH2 suppresses methylation of lysine 27 in histone H3. Science 310(5746):306-310. doi:10.1126/science.1118947

3. Chen Y, Lin MC, Yao H, Wang H, Zhang AQ, Yu J, Hui CK, Lau GK, He ML, Sung J, Kung HF (2007) Lentivirus-mediated RNA interference targeting enhancer of zeste homolog 2 inhibits hepatocellular carcinoma growth through down-regulation of stathmin. Hepatology 46(1):200-208. doi:10.1002/hep.21668

4. Chowdhury R, Yeoh KK, Tian YM, Hillringhaus L, Bagg EA, Rose NR, Leung IK, Li XS, Woon EC, Yang M, McDonough MA, King ON, Clifton IJ, Klose RJ, Claridge TD, Ratcliffe PJ, Schofield CJ, Kawamura A (2011) The oncometabolite 2-hydroxyglutarate inhibits histone lysine demethylases. EMBO Rep 12(5):463-469. doi:10.1038/embor.2011.43

5. Cloughesy TF, Mischel PS (2011) New strategies in the molecular targeting of glioblastoma: how do you hit a moving target? Clin Cancer Res Off J Am Assoc Cancer Res 17(1):6-11. doi: 10.1158/1078-0432.CCR-09-2268

6. Dalgliesh GL, Furge K, Greenman C, Chen L, Bignell G, Butler A, Davies H, Edkins S, Hardy C, Latimer C, Teague J, Andrews J, Barthorpe S, Beare D, Buck G, Campbell PJ, Forbes S, Jia M, Jones D, Knott H, Kok CY, Lau KW, Leroy C, Lin ML, McBride DJ, Maddison M, Maguire S, McLay K, Menzies A, Mironenko T, Mulderrig L, Mudie L, O’Meara S, Pleasance E, Rajasingham A, Shepherd R, Smith R, Stebbings L, Stephens P, Tang G, Tarpey PS, Turrell K, Dykema KJ, Khoo SK, Petillo D, Wondergem B, Anema J, Kahnoski RJ, Teh BT, Stratton MR, Futreal PA (2010) Systematic sequencing of renal carcinoma reveals inactivation of histone modifying genes. Nature 463(7279):360 363. doi:10.1038/nature 08672

7. Dang L, White DW, Gross S, Bennett BD, Bittinger MA, Driggers EM, Fantin VR, Jang HG, Jin S, Keenan MC, Marks KM, Prins RM, Ward PS, Yen KE, Liau LM, Rabinowitz JD, Cantley LC, Thompson CB, Vander Heiden MG, Su SM (2009) Cancerassociated IDH1 mutations produce 2-hydroxyglutarate. Nature 462(7274):739-744. doi:10.1038/nature08617

8. Dhayalan A, Tamas R, Bock I, Tattermusch A, Dimitrova E, Kudithipudi S, Ragozin S, Jeltsch A The ATRX-ADD domain binds to $\mathrm{H} 3$ tail peptides and reads the combined methylation state of K4 and K9. Hum Mol Genet 20(11):2195-2203. doi: $10.1093 / \mathrm{hmg} / \mathrm{ddr} 107$

9. Dolecek TA, Propp JM, Stroup NE, Kruchko C (2012) CBTRUS statistical report: primary brain and central nervous system tumors diagnosed in the United States in 2005-2009. Neurooncology 14(Suppl 5):v1-v49. doi:10.1093/neuonc/nos218

10. Eckert A, Kloor M, Giersch A, Ahmadi R, Herold-Mende C, Hampl JA, Heppner FL, Zoubaa S, Holinski-Feder E, Pietsch T, 
Wiestler OD, von Knebel Doeberitz M, Roth W, Gebert J (2007) Microsatellite instability in pediatric and adult high-grade gliomas. Brain Pathol 17(2):146-150. doi:10.1111/j.1750-3639. 2007.00049.x

11. Edmunds JW, Mahadevan LC, Clayton AL (2008) Dynamic histone $\mathrm{H} 3$ methylation during gene induction: HYPB/Setd2 mediates all H3K36 trimethylation. EMBO J 27(2):406-420. doi: 10.1038/sj.emboj.7601967

12. Gerlinger M, Rowan AJ, Horswell S, Larkin J, Endesfelder D, Gronroos E, Martinez P, Matthews N, Stewart A, Tarpey P, Varela I, Phillimore B, Begum S, McDonald NQ, Butler A, Jones D, Raine K, Latimer C, Santos CR, Nohadani M, Eklund AC, Spencer-Dene B, Clark G, Pickering L, Stamp G, Gore M, Szallasi Z, Downward J, Futreal PA, Swanton C (2012) Intratumor heterogeneity and branched evolution revealed by multiregion sequencing. N Engl J Med 366(10):883-892. doi: 10.1056/NEJMoa1113205

13. Iwase S, Xiang B, Ghosh S, Ren T, Lewis PW, Cochrane JC, Allis CD, Picketts DJ, Patel DJ, Li H, Shi Y (2011) ATRX ADD domain links an atypical histone methylation recognition mechanism to human mental-retardation syndrome. Nat Struct Mol Biol 18(7):769-776. doi:10.1038/nsmb.2062

14. Jiao Y, Killela PJ, Reitman ZJ, Rasheed AB, Heaphy CM, de Wilde RF, Rodriguez FJ, Rosemberg S, Oba-Shinjo SM, Marie SK, Bettegowda C, Agrawal N, Lipp E, Pirozzi C, Lopez G, He Y, Friedman H, Friedman AH, Riggins GJ, Holdhoff M, Burger P, McLendon R, Bigner DD, Vogelstein B, Meeker AK, Kinzler KW, Papadopoulos N, Diaz LA, Yan H (2012) Frequent ATRX, $\mathrm{CIC}$, and FUBP1 mutations refine the classification of malignant gliomas. Oncotarget 3(7):709-722 (pii:588)

15. Jones DT, Jager N, Kool M, Zichner T, Hutter B, Sultan M, Cho YJ, Pugh TJ, Hovestadt V, Stutz AM, Rausch T, Warnatz HJ, Ryzhova M, Bender S, Sturm D, Pleier S, Cin H, Pfaff E, Sieber L, Wittmann A, Remke M, Witt H, Hutter S, Tzaridis T, Weischenfeldt J, Raeder B, Avci M, Amstislavskiy V, Zapatka M, Weber UD, Wang Q, Lasitschka B, Bartholomae CC, Schmidt M, von Kalle C, Ast V, Lawerenz C, Eils J, Kabbe R, Benes V, van Sluis P, Koster J, Volckmann R, Shih D, Betts MJ, Russell RB, Coco S, Tonini GP, Schuller U, Hans V, Graf N, Kim YJ, Monoranu C, Roggendorf W, Unterberg A, Herold-Mende C, Milde T, Kulozik AE, von Deimling A, Witt O, Maass E, Rossler J, Ebinger M, Schuhmann MU, Fruhwald MC, Hasselblatt M, Jabado N, Rutkowski S, von Bueren AO, Williamson D, Clifford SC, McCabe MG, Collins VP, Wolf S, Wiemann S, Lehrach H, Brors B, Scheurlen W, Felsberg J, Reifenberger G, Northcott PA, Taylor MD, Meyerson M, Pomeroy SL, Yaspo ML, Korbel JO, Korshunov A, Eils R, Pfister SM, Lichter P (2012) Dissecting the genomic complexity underlying medulloblastoma. Nature 488(7409):100-105. doi:10.1038/nature11284

16. Kannan K, Inagaki A, Silber J, Gorovets D, Zhang J, Kastenhuber ER, Heguy A, Petrini JH, Chan TA, Huse JT (2012) Wholeexome sequencing identifies ATRX mutation as a key molecular determinant in lower-grade glioma. Oncotarget 3(10):1194-1203.

17. Kent WJ, Sugnet CW, Furey TS, Roskin KM, Pringle TH, Zahler AM, Haussler D (2002) The human genome browser at UCSC. Genome Res 12(6):996-1006. doi:10.1101/gr.229102.Article publishedonlinebeforeprintinMay2002

18. Khuong-Quang DA, Buczkowicz P, Rakopoulos P, Liu XY, Fontebasso AM, Bouffet E, Bartels U, Albrecht S, Schwartzentruber J, Letourneau L, Bourgey M, Bourque G, Montpetit A, Bourret G, Lepage P, Fleming A, Lichter P, Kool M, von Deimling A, Sturm D, Korshunov A, Faury D, Jones DT, Majewski J, Pfister SM, Jabado N, Hawkins C (2012) K27M mutation in histone $\mathrm{H} 3.3$ defines clinically and biologically distinct subgroups of pediatric diffuse intrinsic pontine gliomas. Acta Neuropathol 124(3):439-447. doi:10.1007/s00401-012-0998-0
19. Khuong-Quang DA, Gerges N, Jabado N (2012) Mutations in histone $\mathrm{H} 3.3$ and chromatin remodeling genes drive pediatric and young adult glioblastomas. Med Sci M/S 28(10):809-812. doi: 10.1051/medsci/20122810004

20. Lai A, Kharbanda S, Pope WB, Tran A, Solis OE, Peale F, Forrest WF, Pujara K, Carrillo JA, Pandita A, Ellingson BM, Bowers CW, Soriano RH, Schmidt NO, Mohan S, Yong WH, Seshagiri S, Modrusan Z, Jiang Z, Aldape KD, Mischel PS, Liau LM, Escovedo CJ, Chen W, Nghiemphu PL, James CD, Prados MD, Westphal M, Lamszus K, Cloughesy T, Phillips HS (2011) Evidence for sequenced molecular evolution of IDH1 mutant glioblastoma from a distinct cell of origin. J Clin Oncol Off J Am Soc Clin Oncol 29(34):4482-4490. doi:10.1200/JCO.2010.33. 8715

21. Liu XY, Gerges N, Korshunov A, Sabha N, Khuong-Quang DA, Fontebasso AM, Fleming A, Hadjadj D, Schwartzentruber J, Majewski J, Dong Z, Siegel P, Albrecht S, Croul S, Jones DT, Kool M, Tonjes M, Reifenberger G, Faury D, Zadeh G, Pfister S, Jabado N (2012) Frequent ATRX mutations and loss of expression in adult diffuse astrocytic tumors carrying IDH1/IDH2 and TP53 mutations. Acta Neuropathol 124(5):615-625. doi: 10.1007/s00401-012-1031-3

22. Lu C, Ward PS, Kapoor GS, Rohle D, Turcan S, Abdel-Wahab O, Edwards CR, Khanin R, Figueroa ME, Melnick A, Wellen KE, O'Rourke DM, Berger SL, Chan TA, Levine RL, Mellinghoff IK, Thompson CB (2012) IDH mutation impairs histone demethylation and results in a block to cell differentiation. Nature 483(7390):474-478. doi:10.1038/nature 10860

23. Maksimovic J, Gordon L, Oshlack A (2012) SWAN: subsetquantile within array normalization for illumina infinium $\mathrm{Hu}-$ manMethylation450 BeadChips. Genome Biol 13(6):R44. doi: 10.1186/gb-2012-13-6-r44

24. The 1000 Genomes Project Consortium (2010) A map of human genome variation from population-scale sequencing. Nature 467(7319):1061-1073. doi:10.1038/nature09534

25. Martin C, Cao R, Zhang Y (2006) Substrate preferences of the EZH2 histone methyltransferase complex. The Journal of biological chemistry 281(13):8365-8370. doi:10.1074/jbc.M5134 25200

26. Noushmehr H, Weisenberger DJ, Diefes K, Phillips HS, Pujara K, Berman BP, Pan F, Pelloski CE, Sulman EP, Bhat KP, Verhaak RG, Hoadley KA, Hayes DN, Perou CM, Schmidt HK, Ding L, Wilson RK, Van Den Berg D, Shen H, Bengtsson H, Neuvial P, Cope LM, Buckley J, Herman JG, Baylin SB, Laird PW, Aldape $\mathrm{K}$ (2010) Identification of a $\mathrm{CpG}$ island methylator phenotype that defines a distinct subgroup of glioma. Cancer Cell 17(5):510-522. doi:10.1016/j.ccr.2010.03.017

27. Parsons DW, Jones S, Zhang X, Lin JC, Leary RJ, Angenendt P, Mankoo P, Carter H, Siu IM, Gallia GL, Olivi A, McLendon R, Rasheed BA, Keir S, Nikolskaya T, Nikolsky Y, Busam DA, Tekleab H, Diaz LA Jr, Hartigan J, Smith DR, Strausberg RL, Marie SK, Shinjo SM, Yan H, Riggins GJ, Bigner DD, Karchin R, Papadopoulos N, Parmigiani G, Vogelstein B, Velculescu VE, Kinzler KW (2008) An integrated genomic analysis of human glioblastoma multiforme. Science 321(5897):1807-1812. doi: $10.1126 /$ science. 1164382

28. Rozen S, Skaletsky H (2000) Primer3 on the WWW for general users and for biologist programmers. Methods Mol Biol 132: 365-386

29. Sasaki M, Knobbe CB, Munger JC, Lind EF, Brenner D, Brustle A, Harris IS, Holmes R, Wakeham A, Haight J, You-Ten A, Li WY, Schalm S, Su SM, Virtanen C, Reifenberger G, Ohashi PS, Barber DL, Figueroa ME, Melnick A, Zuniga-Pflucker JC, Mak TW (2012) IDH1(R132H) mutation increases murine haematopoietic progenitors and alters epigenetics. Nature 488(7413):656659. doi:10.1038/nature 11323 
30. Schiffman JD, Hodgson JG, VandenBerg SR, Flaherty P, Polley MY, Yu M, Fisher PG, Rowitch DH, Ford JM, Berger MS, Ji H, Gutmann DH, James CD (2010) Oncogenic BRAF mutation with CDKN2A inactivation is characteristic of a subset of pediatric malignant astrocytomas. Cancer Res 70(2):512-519. doi: 10.1158/0008-5472.CAN-09-1851

31. Schindler G, Capper D, Meyer J, Janzarik W, Omran H, HeroldMende C, Schmieder K, Wesseling P, Mawrin C, Hasselblatt M, Louis DN, Korshunov A, Pfister S, Hartmann C, Paulus W, Reifenberger G, von Deimling A (2011) Analysis of BRAF V600E mutation in 1,320 nervous system tumors reveals high mutation frequencies in pleomorphic xanthoastrocytoma, ganglioglioma and extra-cerebellar pilocytic astrocytoma. Acta Neuropathol 121(3):397-405. doi:10.1007/s00401-011-0802-6

32. Schwartzentruber J, Korshunov A, Liu XY, Jones DT, Pfaff E, Jacob K, Sturm D, Fontebasso AM, Quang DA, Tönjes M, Hovestadt V, Albrecht S, Kool M, Nantel A, Konermann C, Lindroth A, Jäger N, Rausch T, Ryzhova M, Korbel JO, Hielscher T, Hauser P, Garami M, Klekner A, Bognar L, Ebinger M, Schuhmann MU, Scheurlen W, Pekrun A, Frühwald MC, Roggendorf W, Kramm C, Dürken M, Atkinson J, Lepage P, Montpetit A, Zakrzewska M, Zakrzewski K, Liberski PP, Dong Z, Siegel P, Kulozik AE, Zapatka M, Guha A, Malkin D, Felsberg J, Reifenberger G, von Deimling A, Ichimura K, Collins VP, Witt H, Milde T, Witt O, Zhang C, Castelo-Branco P, Lichter P, Faury D, Tabori U, Plass C, Majewski J, Pfister SM, Jabado N (2012) Driver mutations in histone $\mathrm{H} 3.3$ and chromatin remodelling genes in paediatric glioblastoma. Nature 482((7384)):226-231. doi:10.1038/nature10833

33. Shimizu A, Asakawa S, Sasaki T, Yamazaki S, Yamagata H, Kudoh J, Minoshima S, Kondo I, Shimizu N (2003) A novel giant gene CSMD3 encoding a protein with CUB and sushi multiple domains: a candidate gene for benign adult familial myoclonic epilepsy on human chromosome 8q23.3-q24.1. Biochem Biophys Res Commun 309(1):143-154

34. So AY, Jung JW, Lee S, Kim HS, Kang KS (2011) DNA methyltransferase controls stem cell aging by regulating BMI1 and EZH2 through microRNAs. PLoS ONE 6(5):e19503. doi: 10.1371/journal.pone.0019503

35. Sturm D, Witt H, Hovestadt V, Khuong-Quang DA, Jones DT, Konermann C, Pfaff E, Tonjes M, Sill M, Bender S, Kool M, Zapatka M, Becker N, Zucknick M, Hielscher T, Liu XY, Fontebasso AM, Ryzhova M, Albrecht S, Jacob K, Wolter M, Ebinger M, Schuhmann MU, van Meter T, Fruhwald MC, Hauch H, Pekrun A, Radlwimmer B, Niehues T, von Komorowski G, Durken M, Kulozik AE, Madden J, Donson A, Foreman NK, Drissi R, Fouladi M, Scheurlen W, von Deimling A, Monoranu C, Roggendorf W, Herold-Mende C, Unterberg A, Kramm CM, Felsberg J, Hartmann C, Wiestler B, Wick W, Milde T, Witt O, Lindroth AM, Schwartzentruber J, Faury D, Fleming A, Zakrzewska M, Liberski PP, Zakrzewski K, Hauser P, Garami M, Klekner A, Bognar L, Morrissy S, Cavalli F, Taylor MD, van Sluis P, Koster J, Versteeg R, Volckmann R, Mikkelsen T, Aldape K, Reifenberger G, Collins VP, Majewski J, Korshunov A, Lichter P, Plass C, Jabado N, Pfister SM (2012) Hotspot mutations in $\mathrm{H} 3 \mathrm{~F} 3 \mathrm{~A}$ and IDH1 define distinct epigenetic and biological subgroups of glioblastoma. Cancer Cell 22(4):425437. doi:10.1016/j.ccr.2012.08.024

36. Sudo T, Utsunomiya T, Mimori K, Nagahara H, Ogawa K, Inoue H, Wakiyama S, Fujita H, Shirouzu K, Mori M (2005) Clinicopathological significance of EZH2 mRNA expression in patients with hepatocellular carcinoma. Br J Cancer 92(9):1754-1758. doi:10.1038/sj.bjc.6602531

37. Tong ZT, Cai MY, Wang XG, Kong LL, Mai SJ, Liu YH, Zhang HB, Liao YJ, Zheng F, Zhu W, Liu TH, Bian XW, Guan XY, Lin MC, Zeng MS, Zeng YX, Kung HF, Xie D (2012) EZH2 supports nasopharyngeal carcinoma cell aggressiveness by forming a corepressor complex with HDAC1/HDAC2 and Snail to inhibit E-cadherin. Oncogene 31(5):583-594. doi:10.1038/onc.2011.254

38. Turcan S, Rohle D, Goenka A, Walsh LA, Fang F, Yilmaz E, Campos C, Fabius AW, Lu C, Ward PS, Thompson CB, Kaufman A, Guryanova O, Levine R, Heguy A, Viale A, Morris LG, Huse JT, Mellinghoff IK, Chan TA (2012) IDH1 mutation is sufficient to establish the glioma hypermethylator phenotype. Nature 483(7390):479-483. doi:10.1038/nature 10866

39. Varela I, Tarpey P, Raine K, Huang D, Ong CK, Stephens P, Davies H, Jones D, Lin ML, Teague J, Bignell G, Butler A, Cho J, Dalgliesh GL, Galappaththige D, Greenman C, Hardy C, Jia M, Latimer C, Lau KW, Marshall J, McLaren S, Menzies A, Mudie L, Stebbings L, Largaespada DA, Wessels LF, Richard S, Kahnoski RJ, Anema J, Tuveson DA, Perez-Mancera PA, Mustonen V, Fischer A, Adams DJ, Rust A, Chan-on W, Subimerb C, Dykema K, Furge K, Campbell PJ, Teh BT, Stratton MR, Futreal PA (2011) Exome sequencing identifies frequent mutation of the SWI/SNF complex gene PBRM1 in renal carcinoma. Nature 469(7331):539-542. doi:10.1038/nature09639

40. Villard L, Gecz J, Mattei JF, Fontes M, Saugier-Veber P, Munnich A, Lyonnet S (1996) XNP mutation in a large family with Juberg-Marsidi syndrome. Nat Genet 12(4):359-360. doi: 10.1038/ng0496-359

41. Wagner EJ, Carpenter PB (2012) Understanding the language of Lys36 methylation at histone H3. Nat Rev Mol Cell Biol 13(2):115-126. doi:10.1038/nrm3274

42. Wu G, Broniscer A, McEachron TA, Lu C, Paugh BS, Becksfort J, Qu C, Ding L, Huether R, Parker M, Zhang J, Gajjar A, Dyer MA, Mullighan CG, Gilbertson RJ, Mardis ER, Wilson RK, Downing JR, Ellison DW, Baker SJ (2012) Somatic histone H3 alterations in pediatric diffuse intrinsic pontine gliomas and non-brainstem glioblastomas. Nat Genet. doi:ng.110210.1038/ng.1102

43. Xu W, Yang H, Liu Y, Yang Y, Wang P, Kim SH, Ito S, Yang C, Wang P, Xiao MT, Liu LX, Jiang WQ, Liu J, Zhang JY, Wang B, Frye S, Zhang Y, Xu YH, Lei QY, Guan KL, Zhao SM, Xiong Y (2011) Oncometabolite 2-hydroxyglutarate is a competitive inhibitor of alpha-ketoglutarate-dependent dioxygenases. Cancer Cell 19(1):17-30. doi:10.1016/j.ccr.2010.12.014

44. Yan H, Parsons DW, Jin G, McLendon R, Rasheed BA, Yuan W, Kos I, Batinic-Haberle I, Jones S, Riggins GJ, Friedman H, Friedman A, Reardon D, Herndon J, Kinzler KW, Velculescu VE, Vogelstein B, Bigner DD (2009) IDH1 and IDH2 mutations in gliomas. N Engl J Med 360(8):765-773. doi:10.1056/NEJMoa 0808710 